\title{
Location Problem of Distribution Center Based on Baumer Walvar Model: Taking Jiaji Logistics as an Example
}

\author{
Hao Chen \\ Shanghai Maritime University, Shanghai, China \\ Email: chenhao19940926@163.com
}

How to cite this paper: Chen, H. (2019) Location Problem of Distribution Center Based on Baumer Walvar Model: Taking Jiaji Logistics as an Example. Open Journal of Business and Management, 7, 1042-1052. https://doi.org/10.4236/ojbm.2019.72070

Received: March 28, 2019

Accepted: April 25, 2019

Published: April 28, 2019

Copyright $\odot 2019$ by author(s) and Scientific Research Publishing Inc. This work is licensed under the Creative Commons Attribution International License (CC BY 4.0).

http://creativecommons.org/licenses/by/4.0/ (c) (i) Open Access

\begin{abstract}
Jiaji Logistics is one of the biggest logistics enterprises in our country, but the survey found that there are still many problems in it, which limits the development of Jiaji logistics. One of the important factors is the location of the distribution center. In order to overcome this difficulty, the location of Jiaji logistics is used scientifically, and it can also help the development of logistics industry in China. First of all, in this paper, by analyzing distribution center location of the relevant literature both at home and abroad, according to oneself the circumstance of master data, choose the Baumov Model for the theme as a solution. Then, the factors affecting the distribution center of Jiaji logistics are selected, and the optimal solution is obtained by the successive approximation method. The final result will be the distribution center capacity, location, volume allocation and so on. The improved model of the Baumov Model was a great help to the location of the Jiaji logistics, which reduced the cost of the Jiaji logistics.
\end{abstract}

\section{Keywords}

Jiaji Logistics, Site Selection, The Baumov Model, Transit Station

\section{Introduction}

In the past two years, the "cost reduction" measures proposed by the logistics industry in our country have achieved good results, but there is still great potential to be exploited, so I do not think that the relevant work can be relaxed. Therefore, we must continue to work hard to transform the logistics industry policy and market environment. We should change the way of scale economy development and improve the industrial structure of logistics industry. We will 
accelerate the upgrading of the logistics industry with scientific and technological innovation as the main and coordinated development.

The total cost of social logistics in China reached Rmb11.1 TN in 2016, and the ratio of social logistics costs to GDP reached 14.9\%, but it fell 1.1 percentage points from last year, according to data released by the China Logistics and Procurement Federation a few days ago. This shows that the total cost of social logistics per 10,000 yuan of GDP is 1490 yuan, which is $6.9 \%$ lower than last year. This has resulted in nearly 800 billion yuan in economic benefits. (source from http://finance.sina.com.cn/roll/2017-03-24/doc-ifycsukm3404270.shtml)

Therefore, reducing logistics costs is a key step to reduce the production costs of enterprises and support the real economic development. In the past few years, the State Council and relevant departments have implemented the Medium-and Long-Term Plan for the Development of the Logistics Industry (2014-2020), and the "Cost Reduction" measures proposed by the logistics industry in our country have achieved good results. According to statistics, from 2013 to 2015, the ratio of total logistics costs to GDP of the whole society was $18 \%, 16.6 \%$ and $16 \%$, respectively; By 2016, China will have completed, four years ahead of schedule, the target set by the Medium-and Long-Term Plan for the Development of the Logistics Industry (2014-2020) to reduce the total cost of social logistics to a GDP ratio of $15 \%$ (source from

http://finance.sina.com.cn/roll/2017-03-24/doc-ifycsukm3404270.shtml).

As we work together to achieve our goals and achieve some modest results, we must not relax, as our country still has great potential to reduce logistics costs. At present, the ratio of total logistics costs to GDP of China's whole society is not only about twice as high as that of the US, Japan and Germany, but also higher than that of India, Brazil and other BRICS countries, and about 5 percentage points above the global average. Based on the current development of China's GDP, if the ratio of total social logistics costs to GDP can reach the level of $9.2 \%$ in the United States in 2010, it can add more than 6000 billion yuan in economic benefits each year. Similarly, the need for enterprises to reduce costs through the logistics industry is very urgent. Up to now, about $40 \%$ of China's manufacturing production costs are still accounted for by logistics, which is much higher than $14 \%$ to $19 \%$ of developed countries.

To sum up, it is urgent to reduce the cost of logistics, so this paper has selected several representative cities of Jiaji Logistics, and will use the Waerfu model to solve the problem of location of distribution centers that generate transportation costs and cause scale and economic costs of distribution centers., It provides a convenient and effective calculation method for the location of distribution center. The first chapter introduces the background and significance of the topic selection from the current situation of logistics industry, the demand of policy and the requirement of cost. The second chapter mainly describes the concept of distribution center and the importance to logistics enterprises and the logistics industry as a whole. The third chapter mainly expounds the logistics of Jiaji, and introduces the current situation and existing problems of Jiaji logistics. 
The fourth chapter establishes the model and brings the data into the model to obtain the optimal scheme that satisfies the objective function and corresponding constraints. The fifth chapter summarizes the options used in the full text and puts forward the shortcomings of this article and prospects for the future.

\section{Literature Review}

The methods of the current scholars in the location of logistics distribution centers are mainly carried out from the following aspects. First, the goal is to optimize the total cost of logistics distribution centers; The second is to focus on the maximum efficiency of the distribution center to propose the construction of the distribution center, and calculate the scale capacity of the distribution center.

Guo, P. \& Cheng, W. [1] In order to improve the site selection efficiency of urban logistics distribution centers, through the actual construction and operation of the distribution center, a mathematical model with a minimum total cost is constructed, using a genetic algorithm based on integer coding. It solves and the results sought can effectively help planners implement logistics node selection. Gafurov, I. et al. [2] based on the basic operation process of the OEM's parts logistics distribution center, based on various aspects, established the KPI index evaluation system, and used the analytic hierarchy process to compare the relative weights of each indicator. The analysis and calculation are carried out to provide reference and reference for the performance evaluation of the automobile OEM logistics distribution center. Ye, L. et al. [3] constructed a method for logistics location evaluation based on intuitionistic fuzzy numbers by using fuzzy number continuous ordered weighting operator to triangular fuzzy number set in intuitionistic fuzzy numbers. Finally, empirical analysis of a certain enterprise logistics The process of site selection for a distribution center. Zevgolis, IE et al. [4] constructed a hybrid genetic algorithm based on genetic algorithm and tabu search algorithm combined with greedy algorithm to improve crossover operator for the location of cold chain logistics distribution center. This improved hybrid genetic algorithm can effectively avoid premature and local optimal phenomena, obtain higher quality solutions, and further improve computational efficiency. Dablanc, L., \& Ross, C. [5]. Site selection enables the efficiency of cigarette logistics to be improved. Aiming at this problem, this paper introduces the hybrid frog leaping algorithm to solve the complex nonlinear mixed integer programming model. The hybrid frog leaping algorithm used in this paper has the characteristics of strong searching ability and fast convergence speed, and the improved DEA based on this paper. The node logistics capability optimization can accurately evaluate the logistics capacity of the cigarette distribution center. Zhao, C. et al. [6] proposed a discrete firefly algorithm (IGSO) to solve the location problem of the distribution center. The integer is used to encode the problem, the Hamming distance is introduced to measure the distance between the firefly individuals, and a new individual location update construction method is adopted. The algorithm obtained by matlab has good effects on stability 
and operation efficiency. Hui, YV et al. [7] used the comprehensive evaluation method and algorithm of fuzzy linear programming to transform the singleobjective fuzzy programming model of logistics distribution center location into multi-objective decision-making problem. Using correlation coefficient method, evaluate each candidate with trapezoidal fuzzy number. The selection criteria of the site scheme and the weight of the evaluation index, and based on the superiority coefficient, the fuzzy linear programming with the trapezoidal fuzzy number in the constraint condition is transformed into the classical linear programming, and the example is explained.

Some scholars mainly analyze the strategy of the lowest total cost of the logistics distribution center, and optimize the cost allocation through different methods, and finally achieve the goal of optimizing the total cost of the logistics system. Min, LI, \& Guo, Q. [8] On the basis of product management costs and fixed costs, the time limit of distribution centers and users is increased, and the total cost of the distribution center is minimized, thus establishing time-constrained The single location distribution model is solved and finally the distribution center location under different constraints is obtained, which provides a large amount of support for the majority of enterprises. Srinivasan, MM [9] and Pinedo, M. [10] proposed a method to ensure the freshness and quality of fresh products delivered to the consumer field under the "Internet+" environment. She believes that the model can optimize the location of the distribution center, improve the logistics distribution efficiency of fresh agricultural products, effectively meet the consumer demand for freshness, quality and delivery time window of fresh produce, and reduce the distribution cost of logistics enterprises. Guan, X. [11]'s optimization model aims to minimize the logistics cost and maximize the logistics service capability, and establish a multi-objective optimization location model. By adding parameters and applying constraint processing methods, the location problem is turned into a single. The target constrained optimization problem is solved by the improved particle swarm optimization algorithm embedded in the steepest descent method. The results show that the established location model has good practicability.Wen-Jin.et al. [12] believes that in the problem of site selection of cold chain logistics distribution center, the cargo damage of cold chain logistics goods can also be regarded as part of logistics cost. The storage time and temperature of cold chain logistics are matched with the delivery goods. The damage of goods has an important impact. Combined with the influence of transportation time and storage temperature on the change of food quality during storage and transportation, the minimum cost model for the location of cold chain logistics distribution center is established. Martino, D. D.et al. [13] found that the cargo damage has a significant impact on the cost of cold chain logistics. The cargo damage is obviously affected by the storage and transportation temperature and the value of the goods. The impact of the cold chain logistics energy consumption on the cost of the entire cold chain is not obvious. Bozorgi-Amiri.et al. [14] constructed a multi-product 
three-tier logistics based on the consideration of the vehicle load and travel distance constraints and the distribution center's processing capability constraints in order to solve the problems of transshipment, distribution, location and vehicle routing. The network location-path model, with the goal of minimum total cost, proposes a hybrid heuristic algorithm based on greedy random adaptive search algorithm and mileage saving algorithm. The solution shows that the algorithm is feasible and compared with other algorithms. The algorithm is efficient. In this paper, the improved Baumerwal model will be used to study the location of the distribution center, and the method of site selection in the distribution will be enriched to provide reference for enterprises.

\section{The Application of Baumerwal Model in Logistics and Distribution}

Logistics center distribution Transportation Process is as follows [15] as shown in Figure 1.

As you can see from the top right, the goods are from $\mathrm{k}$ factories to $\mathrm{m}$ transfer stations to $\mathrm{n}$ customers. Then the problem is usually considered when the total cost is the smallest.

It can be seen intuitively from the above figure that his total cost consists of four parts: 1) the cost from the factory to the transfer station; 2) the sum of the costs from the transfer station to the customer; 3 ) the fixed cost of the transfer station; Change fee of transfer station.

The alphabet is shown separately:

$W$-Value representing total cost,

$C_{i j}$-Freight per unit from factory i to transit station $\mathrm{j}$,

$X_{i j}$-Total traffic from factory $\mathrm{i}$ to transit station $\mathrm{j}$,

$U_{j t}$-Freight per unit from transit station $\mathrm{j}$ to customer $\mathrm{t}$,

$Y_{j t}$-Total traffic from transit station $\mathrm{j}$ customer $\mathrm{t}$,

$Z_{j}$-Fixed cost of transit station $\mathrm{j}$,

$V_{j}$-Rate of change through unit traffic at transit meter $\mathrm{j}$,

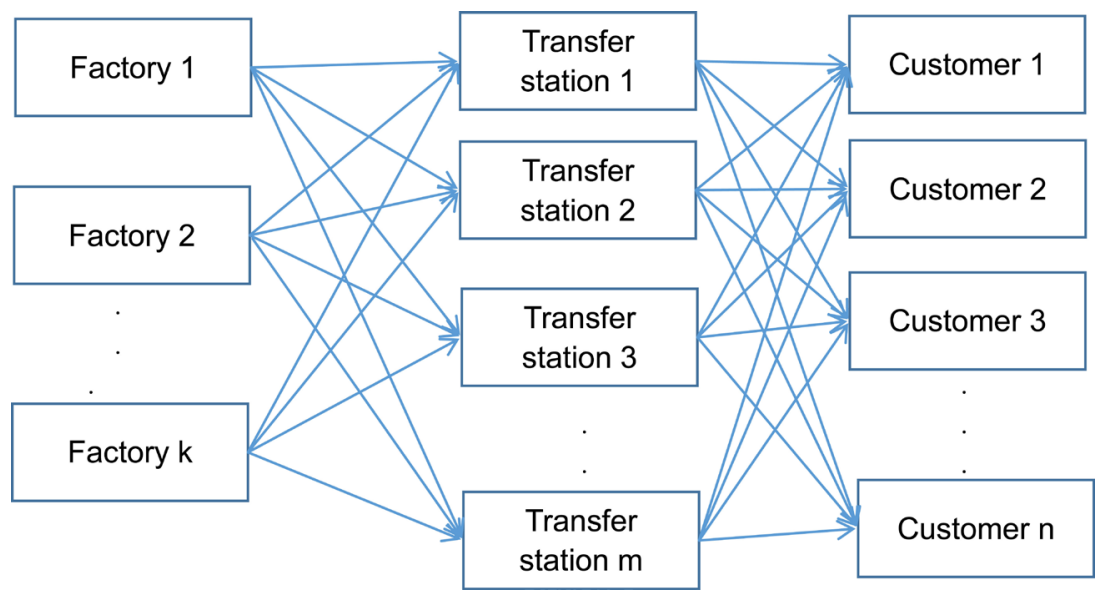

Figure 1. Transportation process. 
$r_{j}$-When the flow of $\mathrm{j}>0, r_{j}=1$; When the flow of $\mathrm{j}=0, r_{j}=0$.

So the objective function is

$$
\operatorname{Min} W=\sum_{i=1}^{k} \sum_{j=1}^{m} C_{i j} X_{i j}+\sum_{j=1}^{m} \sum_{t=1}^{n} U_{j t} Y_{j t}+\sum_{j=1}^{m}\left(V_{j} \times \sum_{i=1}^{k} X_{i j}\right)+\sum_{j=1}^{m} Z_{j} \times r_{j}
$$

Then the constraint corresponding to the objective function is

$$
\begin{aligned}
\sum_{j=1}^{m} X_{i j} & =A_{i}(i=1,2,3 \cdots k) \\
\sum_{t=1}^{n} Y_{i t} & =B_{t}(t=1,2,3 \cdots n) \\
\sum_{i=1}^{k} X_{i j} & =\sum_{t=1}^{n} Y_{j t}(j=1,2,3 \cdots m) \\
X, Y & >0
\end{aligned}
$$

$A_{i}$ - Total quantity of goods in factory I,

$B_{t}$-Customert's demand for the product.

\section{Jiaji Logistics Center Location Results and Analysis}

In the actual process, the entire cargo of Jiaji Logistics is definitely transported from point to point, and bulk cargo often leads to the loss of capacity, while Jiaji Logistics must be from 5 factories (Chongqing, Chengdu, Xi'an, Zhengzhou, Lanzhou) Shipping goods to coastal cities (Guangzhou, Shanghai, Hangzhou, Tianjin) ready for export, the company identified five distribution centers as options, namely: Wuhan, Nanchang, Guiyang, Changsha, Shijiazhuang. It is now possible to select a number of these five options as distribution centres, so that the total distribution costs are minimized. Each candidate will consider economies of scale, that is, the non-linear relationship between distribution centre storage costs and cargo throughput.

Origin/factory alternative destination/customer as shown in Figure 2.

Assumptions in this case:

1) The maximum capacity of each transit station is 5000 tons.

2) Every shipment can be disposed of quickly.

3) At the end of the month, there will be no accumulation.

4) All customer needs can be met.

5) All means of transport are the same, so the speed of transportation is the same.

6) The fixed cost per distribution centre is $\$ 50,000$.

The freight volume from factory to customer as follow as shown in Table 1.

Freight rates from transit stations to customers as shown in Table 2.

Freight rates from factory to transfer station as shown in Table 3.

The variable cost of each transfer station (yuan/ton) as as shown in Table 4.

Through the above known conditions, the solution steps are:

Step 1: Find the initial result, the solution with the lowest total cost $B=\min$ $\left(C_{i j}+U_{j t}\right)$ is as shown in Table 5. 


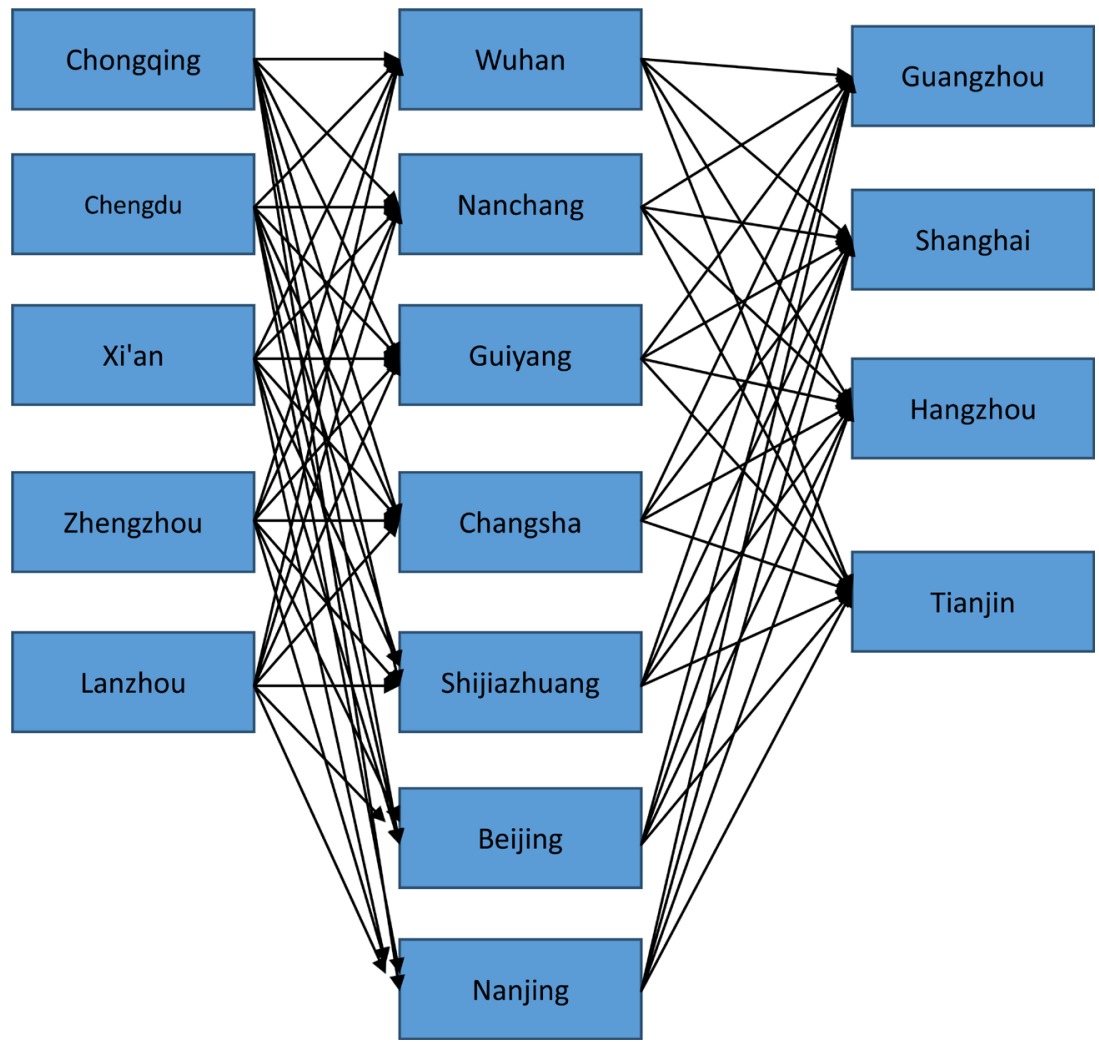

Figure 2. Transportation route.

Table 1. Freight volume (Source from http://www.chinabgao.com/stat/stats/266766.html).

\begin{tabular}{cccccc}
\hline Network/freight volume & Shanghai & Hangzhou & Tianjin & Guangzhou & Tonnage \\
\hline Zhengzhou & 1379 & 28 & 568 & 128 & 2103 \\
Xi'an & 939 & 212 & 936 & 414 & 2501 \\
Chengdu & 1814 & 466 & 736 & 349 & 3365 \\
Lanzhou & 1408 & 178 & 723 & 326 & 2635 \\
Chongqing & 2210 & 664 & 958 & 587 & 4419 \\
Traffic volume & 7750 & 1548 & 3921 & 1804 & \\
\hline
\end{tabular}

Table 2. Freight rates (Source from http://www.jiajiwl.net/shjjwljgcx.html).

\begin{tabular}{|c|c|c|c|c|c|}
\hline Freight rate & Shanghai & Hangzhou & Tianjin & Guangzhou & Yuan per ton \\
\hline Nanjing & 570 & 660 & 1810 & 1360 & \\
\hline Wuhan & 1620 & 1380 & 1510 & 1380 & \\
\hline Beijing & 1850 & 1380 & 450 & 1790 & \\
\hline Guiyang & 1850 & 1950 & 2130 & 1460 & \\
\hline Nanchang & 1620 & 920 & 1570 & 1230 & \\
\hline Changsha & 1700 & 1750 & 1700 & 1500 & \\
\hline Shijiazhuang & 1340 & 1380 & 620 & 1810 & \\
\hline
\end{tabular}


Table 3. Freight rates (Source from http://www.jiajiwl.net/shjjwljgcx.html).

\begin{tabular}{cccccc}
\hline Freight rate yuan/ton & Zhengzhou & Xi'an & Chengdu & Lanzhou & Chongqing \\
\hline Nanjing & 1270 & 1790 & 2240 & 1610 & 2240 \\
Wuhan & 920 & 1290 & 1610 & 1650 & 1770 \\
Beijing & 1210 & 1750 & 1960 & 2350 & 2020 \\
Guiyang & 1680 & 1790 & 900 & 2300 & 750 \\
Nanchang & 1150 & 1460 & 1850 & 1300 & 1500 \\
Changsha & 1550 & 1200 & 400 & 1550 & 550 \\
Shijiazhuang & 850 & 1710 & 1290 & 2070 & 1790 \\
\hline
\end{tabular}

Table 4. Variable cost.

\begin{tabular}{|c|c|c|c|c|c|c|c|}
\hline Options & Nanjing & Wuhan & Beijing & Guiyang & Nanchang & Changsha & Shijiazhuang \\
\hline $\begin{array}{c}\text { Variable } \\
\text { cost }\end{array}$ & 2500 & 3000 & 4000 & 2000 & 2500 & 3000 & 3000 \\
\hline
\end{tabular}

Table 5. The lowest total cost.

\begin{tabular}{ccccc}
\hline Dot/freight & Shanghai & Hangzhou & Tianjin & Guangzhou \\
\hline Zhengzhou & 1840 (South) & 1930 (South) & 1470 (stone) & 2300 (Wuhan) \\
Xi'an & 2360 (South) & 2380 (Chang) & 1200 (long) & 2670 (Wuhan) \\
Chengdu & 2100 (long) & 2150 (long) & 1910 (stone) & 1900 (long) \\
Lanzhou & 2180 (South) & 2220 (Chang) & 2690 (stone) & 2530 (Chang) \\
Chongqing & 2250 (long) & 2300 (long) & 2250 (long) & 2050 (long) \\
\hline
\end{tabular}

Table 6. The optimal solution.

\begin{tabular}{ccccc}
\hline Dot/freight & Shanghai & Hangzhou & Tianjin & Guangzhou \\
\hline Zhengzhou & 5000 (south) & & 1761 (stone) & \\
Xi'an & & & 2250 (long) & \\
Chengdu & 2750 (long) & & & 1804 (Chang) \\
Lanzhou & & 1548 (Chang) & & \\
Chongqing & & & & \\
\hline
\end{tabular}

From Table 5, the optimal solution can be found, as shown in Table 6.

PS: Due to the lower cost of Changsha than Nanchang in the Hangzhou option, Nanchang was chosen as a transit point because the change cost of Nanchang was lower than that of Changsha. Since the storage capacity is up to 5000, it is calculated at the minimum freight rate.

Since only transport costs are accounted for in the table above, the variable costs and fixed costs for each distribution centre are not taken into account. Since the fixed costs for each distribution centre are $\$ 50,000$, the change costs and fixed costs are added to compare the changes and the impact on the results. 
Step 2: The initial solution can obtain the liquidity of each candidate place and the corresponding average unit variable cost (average unit variable cost $=$ unit variable cost ${ }^{\star} \alpha^{\star}$ liquidity/flux of liquidity). The results are shown in Table 7 below:

PS: $\alpha$ reflects the non-linear relationship between unit variable cost and liquidity $(0<\alpha<1)$.

Add the average variable cost to the minimum cost table to get the minimum comprehensive cost as shown in Table 8 .

Repeat the work of step 1, find the quadratic solution, the average variable cost, and the minimum comprehensive cost table. The step 3 and step 4 are repeated. When the result does not change again, it is the optimal solution. I added a 0 - 1 plan to the original model. From the above figure, I took 1 from the city that was selected as the distribution center. Then we can see very intuitively that Nanjing, Guiyang, Nanchang, Changsha, Shijiazhuang became the distribution center. And from the above figure, we can see the distribution of traffic from the factory to the transit station, and the distribution of traffic from the transit station to the customer. The most important thing is that the minimum cost is also calculated to be 7,301,620 yuan, and also the flow of various transit stations. As can be seen from the figure:

Xi'an 953 tons of cargo and Lanzhou 2635 tons of cargo were shipped to Nanjing for transit; From Chongqing, 966 tons of goods pass through Nanjing; Xi'an 1548 tons of cargo transited from Nanchang; Chengdu has 1547 tons of cargo and 3453 tons of cargo in Chongqing transited from Changsha; Zhengzhou has 2103 tons of cargo and Chengdu has 1818 tons of cargo transit from Shijiazhuang.

After the integration, distribution, and re-scheduling of transit stations, the traffic volume from Nanjing to Shanghai was 3588 tons, from Guiyang to Guangzhou was 966 tons, from Nanchang to Guangzhou was 1548 tons, and from

Table 7. Average unit variable cost.

\begin{tabular}{cccccccc}
\hline Candidate point & Nanjing & Wuhan & Beijing & Guiyang & Nanchang & Changsha & Shijiazhuang \\
\hline Liquidity & 5000 & 0 & 0 & 0 & 3352 & 5000 & 1761 \\
$\begin{array}{c}\text { Average variable } \\
\text { cost }\end{array}$ & 17.6 & & & & 21.6 & 21.2 & 35.7 \\
\hline
\end{tabular}

Table 8. Minimum comprehensive cost.

\begin{tabular}{ccccc}
\hline Dot/freight & Shanghai & Hangzhou & Tianjin & Guangzhou \\
\hline Zhengzhou & 1857.6 (South) & 1947.6 (South) & 1505.7 (stone) & 2300 (Wuhan) \\
Xi'an & 2377.6 (South) & 2401.6 (Chang) & 1221.2 (long) & 2670 (Wuhan) \\
Chengdu & 2121.2 (long) & 2171.2 (long) & 1945.7 (stone) & 1921.2 (long) \\
Lanzhou & 2197.6 (South) & 2241.6 (Chang) & 2725.7 (stone) & 2551.6 (Chang) \\
Chongqing & 2271.2 (long) & 2321.2 (long) & 2271.2 (long) & 2071.2 (long) \\
\hline
\end{tabular}


Changsha to Shanghai was 4162 tons. At the same time, it was 838 tons to Guangzhou. It's 3921 tons from shijiazhuang to Tianjin.

The result is to satisfy the customer's demand, factory output, transit capacity, and ultimately the minimum total cost of the result is the accurate and optimal solution in this case.

\section{Conclusions}

This paper calculates the location of Jiazhi logistics through the Baomowaerfu model. I will summarize the whole text and sum up the shortcomings of this article, and draw up the research prospects. I hope that more in-depth research can be carried out in the future.

What this paper studies is that the improved Baomowaerfu model has certain guiding significance to the optimization of distribution center location. The innovation point of this article compared with the original Baomowaerfu model is:

1) This article introduces the 01 plan, making the entire result more intuitive.

2) This article adds the limit of warehouse capacity.

3) The construction cost and fixed cost of the warehouse are included in this article.

As for the contents of this paper, there are still some future research directions that can be further studied and analyzed:

1) Considering that the customer may become the consignor and the consignor may also be the customer, this article only considers one-way situations, but the two-way situation is unknown.

2) And this article is only a few major cities in the location situation; the sample capacity is small and subjective.

3) The location of this article is only a rough calculation of the general plan, but it does not determine the specific location, but it is determined that in a certain city, this part needs to be studied further.

\section{Conflicts of Interest}

The author declares no conflicts of interest regarding the publication of this paper.

\section{References}

[1] Guo, P. and Cheng, W. (2011) System Modeling and Simulation Analysis of Railway Container Logistic Center. Computer Engineering \& Applications, 47, 235-238.

[2] Gafurov, I., Panasyuk, M. and Pudovik, E. (2014) Interregional Logistic Center as the Growth Point of Regional Economics. Procedia Economics \& Finance, 15, 474-480. https://doi.org/10.1016/S2212-5671(14)00486-9

[3] Ye, L., Liu, X. and Yan, C. (2011) Selection of Logistics Center Location Using Axiomatic Fuzzy Set and Topsis Methodology in Logistics Management. Expert Systems with Applications, 38, 7901-7908. https://doi.org/10.1016/j.eswa.2010.12.161

[4] Zevgolis, I.E., Mavrikos, A.A. and Kaliampakos, D.C. (2004) Construction, Storage 
Capacity and Economics of an Underground Warehousing-Logistics Center in Athens, Greece. Tunnelling \& Underground Space Technology, 19, 165-173. https://doi.org/10.1016/j.tust.2003.11.004

[5] Dablanc, L. and Ross, C. (2012) Atlanta: A Mega Logistics Center in the Piedmont Atlantic Megaregion (PAM). Journal of Transport Geography, 24, 432-442. https://doi.org/10.1016/j.jtrangeo.2012.05.001

[6] Zhao, C., Liu, K. and Li, D.-S. (2004) Application of SOFM Neural Network for Classification and Evaluation of Logistics Center City. China Journal of Highway \& Transport, 17, 119-122.

[7] Hui, Y.V., Leung, L.C., Fu, G. and Cheung, W. (2003) Designing a Fourth-Party e-Commerce Logistics Center: A Benefit, Cost and Risk Analysis Using AHP and ANP Models. International Journal of Internet \& Enterprise Management, 1, 53-74. https://doi.org/10.1504/IJIEM.2003.002441

[8] Min, L.I. and Guo, Q. (2007) Multiple Depot Multi-Logistics Center Distribution Problem. Computer Engineering \& Applications, 43, 202-204.

[9] Srinivasan, M.M., Best, W.D. and Chandrasekaran, S. (2007) Warner Robins Air Logistics Center Streamlines Aircraft Repair and Overhaul. Interfaces, 37, 7-21. https://doi.org/10.1287/inte.1060.0260

[10] Pinedo, M. (1984) Optimal Policies in Stochastic Shop Scheduling. Annals of Operations Research, 1, 305-329. https://doi.org/10.1007/BF01874395

[11] Guan, X., et al. (2009) Study on Logistics Center Location Bi-Level Programming Model and Algorithm Based on Competition. Journal of Wuhan University of Technology, 33, 956-959. https://doi.org/10.1061/41064(358)441

[12] Yu, W.-J. and Liu, K. (2006) The Study on Logistics Center Location Based on ANP. Journal of Transportation Systems Engineering \& Information Technology, 6, 74-77.

[13] Martino, D.D., Dall'Asta, L., Bianconi, G. and Marsili, M. (2009) A Minimal Model for Congestion Phenomena on Complex Networks. Journal of Statistical Mechanics Theory \& Experiment, 8, P08023. https://doi.org/10.1088/1742-5468/2009/08/P08023

[14] Bozorgi-Amiri, A. and Asvadi, S. (2015) A Prioritization Model for Locating Relief Logistic Centers Using Analytic Hierarchy Process with Interval Comparison Matrix. Knowledge-Based Systems, 86, 173-181. https://doi.org/10.1016/j.knosys.2015.06.005

[15] Rosenfeld, K.A., Andrews, S.M., Wilner, D.J. and Stempels, H.C. (2012) A DiskBased Dynamical Mass Estimate for the Young Binary v4046 SGR. Astrophysical Journal, 759, 1445-1449. https://doi.org/10.1088/0004-637X/759/2/119 